\title{
A GESTÃO DO CONHECIMENTO E AS EXPERTIZES DESENVOLVIDAS NO ENSINO SUPERIOR
}

\author{
LA GESTIÓN DEL CONOCIMIENTO Y LAS EXPERIENCIAS \\ DESARROLLADAS EN LA ENSEÑANZA SUPERIOR
}

\author{
THE MANAGEMENT OF KNOWLEDGE AND THE EXPERTISES DEVELOPED \\ IN HIGHER EDUCATION
}

\author{
Arielly Kizzy CUNHA ${ }^{1}$ \\ José Anderson SANTOS CRUZ² \\ José Luís BIZELLI ${ }^{3}$
}

RESUMO: O artigo aprofunda reflexões sobre a gestão do conhecimento frente às inovações tecnológicas, descrevendo aspectos da sociedade atual na busca pela aquisição e estruturação de habilidades para atender um mercado de trabalho em constante mudança. Em um universo laboral cada vez mais empreendedor, o aprimoramento contínuo da força de trabalho para incorporar tecnologias inovadoras é exigência capaz de fazer diferença para ingresso e permanência em organizações complexas. Os centros formadores de profissionais de nível superior devem graduar para atender uma sociedade que demanda lideranças com compromisso social e sólida formação para resolução de desafios tecnológicos através de procedimentos éticos e politicamente corretos. Algumas expertises demandam desenvolvimento ao longo da vida, desde a formação básica até as etapas que se seguem à graduação, e estão relacionadas à construção de relações humanizadas no trabalho através da interação entre os campos profissionais, nos quais trabalhadores são conduzidos a refletir sobre suas ações no contexto social, político, econômico, profissional e tecnológico.

PALAVRAS-CHAVE: Conhecimento. Gestão. Ensino superior.

RESUMEN: El artículo profundiza las reflexiones sobre la gestión del conocimiento frente a las innovaciones tecnológicas, describiendo aspectos de la sociedad actual en la búsqueda de adquirir y estructurar las destrezas para satisfacer un mercado laboral en constante cambio. En un universo laboral cada vez más emprendedor, la mejora continua de la fuerza de trabajo para incorporar tecnologías innovadoras es un requisito que puede marcar la diferencia en el ingreso y permanencia en organizaciones complejas. Los profesionales de nivel superior deben graduarse para encontrarse con una sociedad que exija liderazgos con compromiso social y sólida

${ }^{1}$ Universidade Estadual Paulista (Unesp), Bauru - SP - Brasil. Doutoranda pelo PPG em Mídia e Tecnologia na Faculdade de Arquitetura, Artes e Comunicação - FAAC - UNESP. Email: ariellykizzy@yahoo.com.br

${ }^{2}$ Universidade Estadual Paulista (Unesp), Araraquara - SP - Brasil. Doutorando pelo Programa de Pósgraduação em Educação Escolar na Faculdade de Ciências e Letras - FCLAr. Bolsista CAPES. E-mail: joseandersonsantoscruz@gmail.com

${ }^{3}$ Universidade Estadual Paulista (Unesp), Araraquara - SP - Brasil. Docente do Programa de Pósgraduação em Educação Escolar, FCLAr. Email: bizelli@fclar.unesp.br 
formación para resolver los retos tecnológicos a través de procedimientos éticos y políticamente correctos. Algunas pericias exigen un desarrollo permanente, desde la formación básica hasta los pasos que siguen la graduación, y se relacionan con la construcción de relaciones humanizadas en el trabajo a través de la interacción entre campos profesionales, en los cuales los trabajadores son llevó a reflexionar sobre sus acciones en el contexto social, político, económico, profesional y tecnológico.

PALABRAS-CLAVE: Conocimiento. Gestión. Enseñanza superior.

ABSTRACT: The article deepens Reflections on knowledge management in front of technological innovations, describing aspects of the current society in the quest for acquiring and structuring skills to meet a constantly changing labour market. In an increasingly enterprising labor universe, continuous improvement of the workforce to incorporate innovative technologies is a requirement that can make a difference for ingress and permanence in complex organizations. Top-level professionals trainees must graduate to meet a society that demands leaderships with social commitment and solid formation for solving technological challenges through ethical and politically correct procedures. Some expertises demand lifelong development, from basic training to the steps that follow the graduation, and are related to the construction of humanized relationships in work through the interaction between professional fields, in which workers are led to reflect on their actions in the social, political, economic, professional and technological context.

KEYWORDS: Knowledge. Management. Higher education.

\section{Introdução}

A Gestão do Conhecimento (GC) vem ocupando destaque nos estudos que tratam da construção de habilidades necessárias para que os seres humanos enfrentem o universo do trabalho. Em tempos de acesso ilimitado à informação e de demanda por capacidade de apropriação do conhecimento tecnológico, aliar as variadas formas do saber para viabilizar projetos de desenvolvimento sustentável para comunidades humanas; filtrar dados produzindo informações úteis que se possam transformar em metodologias de ensino e aprendizagem para fins de formação, educação cidadã, empoderando indivíduos para projetos coletivos e participativos; são objetivos institucionais e organizacionais. Hoje, o conhecimento aparece melhor com fonte de poder, tanto para o mercado de trabalho quanto para a circulação dos produtos no mercado de consumo. Conforme Figueiredo (2005), o mundo das informações - sem indivíduos capazes de lhe dar sentido - não é suficiente para resolver as questões humanas. 
A GC, rotineiramente se apresenta superficial, sendo que seu diferencial é mais profundo, de difícil acesso e visualização. É muito comum na sociedade atual os indivíduos atuando em trabalhos, nas pesquisas, em estudos focados fora de suas aspirações potenciais e força de trabalho.

$\mathrm{Na}$ modernidade líquida todos fazem tudo; assim, não é possível aprofundamento na respectiva aptidão.
A ideia de progresso em sua encarnação presente parece tão pouco familiar que chegamos a nos perguntar se ainda a mantemos, é porque o progresso, como tantos outros parâmetros da vida moderna, está agora "individualizado"; mais precisamente - desregulado e privatizado" (BAUMAN, 2001, p. 155).

Pessoas atuando em locais incompatíveis com seus interesses resultam em prejuízos para a ciência, para a economia e para a construção coletiva do conhecimento. Kuhn (1998) expõe a questão da arbitrariedade na ciência, que impede a resolução de problemas, mas que também tem um efeito importante no desenvolvimento científico, já que a escolha dos interesses de estudos e caminhos que a pesquisa do indivíduo vai seguir é individual: "É igualmente necessário que exista uma base para a fé no candidato específico escolhido embora não precise ser, nem racional, nem correta" (KUHN, 1998, p. 199).

Para Figueiredo (2005), quando nessa base há um desarranjo, um desperdício de talentos se instaura, incoerente com a gestão do conhecimento, baseada na descoberta das potencialidades individuais. Assim, a gestão deve se dedicar à identificação e desenvolvimento de potencialidades escondidas.

Como o mundo esta mudando rápido, o que é novo hoje pode estar obsoleto amanhã, criar Políticas e Programas educacionais capazes de preparar um indivíduo a aprender a aprender, tornar-se autônomo e capaz de criar, passou a ser considerado prioridade em muitos países. Há necessidade de uma reforma educacional, que envolve flexibilidade no currículo, na proposta pedagógica, nos métodos de avaliação, na estrutura organizacional e principalmente na profissionalização do professor, como um agente ativo e inovador. (VIDAL; NETO, 2016, p.268)

Nesse cenário, um novo perfil profissional se destaca: é o profissional que desenvolveu aptidões necessárias, de relações humanas e formação profissional com habilidades e competências para lidar com a informação, processos e atuando na Gestão do Conhecimento. 


\section{Gestão do Conhecimento: diálogos e possibilidades}

Drucker (1990) define GC como a capacidade de gerenciar, descobrir, mapear, classificar, captar, distribuir, criar, multiplicar e reter conhecimento com eficiência, eficácia e efetividade para que uma organização se coloque em posição de vantagem competitiva em relação às outras, com o objetivo de gerar lucro e garantir competitividade.

Por sua vez, Nonaka e Takeuchi (1997) entendem a gestão do conhecimento como um processo interativo de criação do conhecimento organizacional, definindo-o como a capacidade que uma empresa tem de criar conhecimento, disseminá-lo na organização e incorporá-lo a produtos, serviços e sistemas.

Tendo em vista a necessidade de manter-se no mercado, que a cada dia torna-se mais competitivo, as empresas procuram modernizar e aumentar a sua capacidade de criar conhecimento, aprimorar o processo de criação.

Apesar disso, sucessões em algumas empresas ainda tendem a ser traumáticas, não por desqualificação dos sucessores, mas porque as empresas não os conhecem, e os talentos não descobertos também não são previamente preparados.

Figueiredo (2005) destaca que além desse desperdício interno, as contratações externas também desestimulam talentos potencialmente capazes para ocupar as vagas em aberto, contrariando a gestão do conhecimento, que deve se dedicar à identificação e desenvolvimento de potencialidades escondidas. A atuação coerente em gestão de conhecimento exige dos gerentes a descoberta perene de talentos nas empresas também para ocupar postos e cargos novos.

Para que se alcance o sucesso é necessário atitude, suporte, conhecimentos, habilidades, experiências, métodos e contexto. Só atitude não basta, é preciso ter a atitude certa, e para distingui-la é necessário o conhecimento.

O mundo contemporâneo traz inúmeras oportunidades, e em contrapartida altera paradigmas já consolidados. A construção do conhecimento passa por revisões permeadas pelas tecnologias.

Levy (1999) expõe que com os avanços da tecnologia, o acesso à educação foi facilitado, democratizando o conhecimento; ele crê que a cibercultura possibilita novos estilos de aprendizagem, facilitando o acesso ao conhecimento. Porém, é preciso escolher e filtrar as informações, organizá-las em grupos e comunidades onde se possa compartilhar interesses e ideias, e criar uma inteligência coletiva. Ainda, o autor 
defende que todos os indivíduos têm a sua própria inteligência acumulada em suas vivências, que é usada para interação social, e que o ciberespaço é um espaço que favorece essas interações, promove intercâmbio de ideias por meio de conexões e comunidades virtuais: assim, novas ideias são construídas, novas formas e possibilidades de se aprender e ensinar.

O que é preciso aprender não pode mais ser planejado nem precisamente definido com antecedência. [...] Devemos construir novos modelos do espaço dos conhecimentos. No lugar de representação em escalas lineares e paralelas, em pirâmides estruturadas em 'níveis', organizadas pela noção de pré-requisitos e convergindo para saberes 'superiores', a partir de agora devemos preferir a imagem em espaços de conhecimentos emergentes, abertos, contínuos, em fluxo, não lineares, se reorganizando de acordo com os objetivos ou os contextos, nos quais cada um ocupa posição singular e evolutiva (LÉVY, 1999, p. 158).

É necessária a capacidade de reconhecer o outro como um sujeito dotado de inteligência, pois os diferentes saberes se complementam, gerando uma comunicação efetiva, compartilhamento de informação e valorização do indivíduo, promovendo um crescimento coletivo (LÉVY, 1999).

O contexto atual exige dos professores novas práticas frente ao conhecimento, com foco no preparo das novas gerações de indivíduos para o pensamento crítico, em contraposição ao uso impensado, frenético e assíduo da aparelhagem tecnológica, com contundente familiaridade e interatividade.

Cada vez mais, as novas gerações correspondem com facilidade aos diversos estímulos provenientes dessa seara, assim, executam paralelamente diferentes atividades, como: estudar, trabalhar, comunicar-se, jogar, entre outras, isto é, transitam com agilidade, desenvoltura nesse ambiente. Assim como manifestam curiosidade, inquietações latentes, resiliência para adaptar-se a esse campo abalizado por frequentes inovações. Por isso, é necessário estabelecer uma relação entre o universo escolar e a arena das tecnologias. Tratase, portanto, de materializar uma formação que oportunize as novas gerações autonomia e competências, como: envergadura argumentativa, flexibilidade, visão crítica diante dos fatos, pensamento autônomo. (ARAUJO; RIBEIRO; PINHEIRO, 2016, p.107).

No mundo contemporâneo a riqueza vem do conhecimento, e as oportunidades são das pessoas que sabem como deve ser feito seu uso, preparo, atualização e atitude, além do envolvimento com o trabalho; essas atitudes são, hoje, diferenciais. 
A tendência é que essa educação atual se volte para o futuro, onde as pessoas aprendam a aprender e refletir ao invés de reproduzir informações; gerar novos conhecimentos é uma nova cultura, que ainda está em processo de transição.

De acordo com o Manual de Oslo (1997), a expressão “economia baseada no conhecimento" descreve as tendências de uma maior dependência de conhecimento, informações e altos níveis de competência e acessibilidade desses dados.

A função estratégica do conhecimento é ressaltada pelos crescentes investimentos em pesquisa, desenvolvimento e educação, que cresceram mais rapidamente que os investimentos físicos na maioria dos países durante as últimas décadas.

A educação reprodutivista, de copiar e decorar, não faz mais sentido, o processo e os argumentos são o que de fato tem valor, a reflexão do "por que", e essa fase de transição pela qual estamos passando é muito complexa.

Hillesheim (2016) entende que as políticas públicas trazem desafios para as pesquisas, fazendo-as deixarem as posições confortáveis e estabelecidas do que seria uma qualidade intrínseca do objeto de pesquisa.

Tsallis (1985) declara que a pesquisa nas universidades é necessária, base da evolução, um bem impreterível. A pesquisa sempre melhora o conteúdo da didática, a essência da aula, amplia o contexto do saber do pesquisador, tornando-o mais rico, definindo seu contorno, acrescentando nuances, com versatilidade, relevo, vida, alegria.

Para o autor, a pesquisa é executada para satisfazer a curiosidade do pesquisador e a curiosidade dos outros, assim sanando essa curiosidade, gerando bem-estar fisiológico, corporal, psíquico, material. "A pesquisa gera prazer: prazer musical, estético, prazer de aceder ao difícil, o prazer da troca, do intercâmbio, no espaço, no tempo" (Tsallis, 1985, p. 570).

A pesquisa gera economia: economia de tempo, economia de energia, economia de recursos do solo, agropecuários, marítimos, humanos, economia de recursos financeiros, monetários. A pesquisa gera autonomia, independência, autogestão, gera real poder de decisão sobre nossos próprios destinos - carências grandes estas no chamado Terceiro Mundo. "Primeiro", para nós que nele vivemos, e dele dependemos. A pesquisa gera notável qualificação nos profissionais de todos os horizontes, gera um potencial humano de dinamismo e versatilidade, gera pessoas conscientes de suas responsabilidades, de suas limitações e de seus talentos, rasga véus de ignorância, preconceitos mistificadores, abre espaços, estimula interações, 
frequentemente interdisciplinares, não raro as mais fecundas. (TSALLIS, 1985, p.571)

O mercado de trabalho reflete também essa realidade, pois procura pessoas que tenham o intuito de participar dessas mudanças culturais e semear novos paradigmas. A tradição intimidadora empresarial hoje dá espaço para as inovações.

Aceita-se atualmente que o desenvolvimento e a difusão de novas tecnologias são essenciais para o crescimento da produção e aumento da produtividade. Nosso entendimento do processo de inovação e seu impacto econômico ainda é deficiente. Por exemplo, estamos claramente vivendo uma importante revolução tecnológica, com a economia mundial sendo reconfigurada pelas novas tecnologias da informação. (OCDE, 1997, p. 15)

A princípio, a tecnologia se desenvolvia através da ciência básica e avançava para a pesquisa aplicada, incorporando-a em aplicações tecnológicas e no marketing. "O novo pensamento sobre inovação fez surgir a importância dos sistemas e levou a uma abordagem mais integrada da formulação e implantação de políticas ligadas à inovação" (OCDE, 1997, p. 31).

Nesse sentido, Figueiredo (2005) relata que há espaço nas corporações para conhecimentos que de imediato não resultem em ações efetivas potencializadas no contexto dos negócios, mas que podem ser aproveitados nas estratégias empresariais. Essas iniciativas ampliam o uso do saber e os ativos intangíveis em benefício da empresa; esses ativos intelectuais podem também fomentar novas atuações, resultados, ampliação de mercado e atração de consumidores, além de gerar inovações, oportunidades e riquezas adicionais.

\section{A formação do indivíduo para o mercado de trabalho contemporâneo}

O profissional que vai atuar nesse contexto se gradua no Ensino Superior; sendo assim, são necessários determinados aprendizados que o prepare para atuar. O Ensino Superior influencia diretamente na formação para o trabalho, principalmente através das tecnologias atuais e da convergência tecnológica, cada vez mais presentes no cotidiano do indivíduo. 
De acordo com o artigo 43 da Lei de Diretrizes e Bases, a Educação Superior tem por finalidade:

I - estimular a criação cultural e o desenvolvimento do espírito científico e do pensamento reflexivo;

II - formar diplomados nas diferentes áreas de conhecimento, aptos para a inserção em setores profissionais e para a participação no desenvolvimento da sociedade brasileira, e colaborar na sua formação contínua;

III - incentivar o trabalho de pesquisa e investigação científica, visando ao desenvolvimento da ciência e da tecnologia e da criação e difusão da cultura, e, desse modo, desenvolver o entendimento do homem e do meio em que vive;

IV - promover a divulgação de conhecimentos culturais, científicos e técnicos que constituem patrimônio da humanidade e comunicar o saber através do ensino, de publicações ou de outras formas de comunicação;

V - suscitar o desejo permanente de aperfeiçoamento cultural e profissional e possibilitar a correspondente concretização, integrando os conhecimentos que vão sendo adquiridos numa estrutura intelectual sistematizadora do conhecimento de cada geração;

VI - estimular o conhecimento dos problemas do mundo presente, em particular os nacionais e regionais, prestar serviços especializados à comunidade e estabelecer com esta uma relação de reciprocidade;

VII - promover a extensão, aberta à participação da população, visando à difusão das conquistas e benefícios resultantes da criação cultural e da pesquisa científica e tecnológica geradas na instituição. (LDB, 1996, art.43)

Ou seja, é no Ensino Superior que se incentiva o pensamento reflexivo, se aprofunda nas respectivas áreas do conhecimento, se incentiva a pesquisa, se divulga informações, se integra conhecimentos, e se promove a extensão com a comunidade, visando a difusão das pesquisas desenvolvidas e o retorno social com aplicabilidade prática dos conceitos teóricos.

A intervenção na realidade através da extensão universitária é um meio de expor aos alunos, em atividades práticas, os "impactos gerados pela intervenção na realidade, provocando, em última instância, a tomada de consciência sobre o 'estar no mundo' na condição de futuro profissional” (PASQUALINI, MARTINS, MIGUEL, 2016, p. 664).

A extensão favorece o compartilhamento do conhecimento desenvolvido na instituição, tanto do ensino quanto da pesquisa, coadunando-o com as necessidades da comunidade e transformando a realidade social.

O Art. 207 da Constituição Federal do Brasil (1988) dispõe sobre as funções básicas da Universidade ao afirmar que: "As universidades gozam de autonomia 
didático-científica, administrativa e de gestão financeira e patrimonial e obedecerão ao princípio da indissociabilidade entre ensino, pesquisa e extensão (BRASIL, 1988).

Com a extensão, a pesquisa recebe retorno sobre suas reais necessidades e consegue se inserir e reconhecer a comunidade social local, numa troca de conhecimentos, valores e culturas.

A partir desse contexto e vivência é possível diagnosticar necessidades de pesquisas e outras ações; em decorrência desse reconhecimento, ocorre o fornecimento de subsídios para o aprimoramento curricular e estrutural da própria Universidade. É uma experiência que propicia principalmente uma formação integral consolidada.

Portanto, os desafios do Ensino Superior vão desde preparar o aluno para integrar a equipe empresarial, perpassando por estimular sua motivação profissional, bem como incentivar sua capacitação constante. É essencial que o profissional vá para o mercado pensando no seu desenvolvimento no que tange ao pensamento sistêmico, o domínio pessoal, os modelos mentais, a construção de uma visão compartilhada e aprendizagem em equipe, alcançando assim uma melhora contínua tanto na gestão quanto nos projetos e soluções.

Considerando que a Educação Superior constitui-se em uma das principais condições para a mobilidade social, à medida que no atual contexto cada vez mais o diploma é requisito no mercado de trabalho, as dificuldades de acesso e permanência apresentam-se como um grande desafio.

Assim, quando os estudantes que conseguem ingressar na Educação Superior não permanecem e não concluem com sucesso o curso escolhido, é preciso repensar o Ensino Superior, suas políticas, a organização, a gestão e o processo pedagógico das instituições de formação.

O esforço dos programas governamentais de acesso e permanência requer a atuação conjunta das instituições e exigem um olhar especial para aqueles estudantes que, em decorrência de dificuldades econômicas, tiveram uma trajetória de escolaridade e de vida que não favorece o sucesso nos cursos que escolherem ou que lhes foi possível escolher. (PEGORINI; GURGEL, 2016, p.34)

Baczinsli e Comar (2016) consideram que na educação escolar os educadores têm o poder de interferir na formação integral do homem, em favor da socialização dos conhecimentos científicos, formando cidadãos com capacidades de atuarem participativamente na sociedade. 
O Professor é um mediador do processo de aprendizado, um pesquisador e gestor. Libâneo (2005) define a Pedagogia como a Ciência da Educação que se caracteriza pela atitude de investigação diante da natureza, das finalidades e dos processos necessários às práticas educativas, que podem ocorrer em diversos contextos, para além da escola.

O desafio do atual profissional da educação não se resume a conduzir aulas tradicionais, mas também preparar os alunos para que sejam engajados e envolvidos.

O papel do pedagogo proporciona ambiente de aprendizado desenvolvendo nas pessoas o intuito das cinco disciplinas utilizadas nas organizações aprendentes, que classificam-se em: pensamento sistêmico, domínio pessoal, modelos mentais, a construção de uma visão compartilhada e aprendizagem em equipe. (SENGE, 2002 p.40).

Essas ações passam pelo entendimento e pelo desenvolvimento dos princípios éticos que regem as relações, bem como de conteúdos e procedimentos que contribuem para que se atinjam os fins propostos pela missão, valores e objetivos das organizações.

Isso ocorre através do processo de educação continuada, e assim se justifica para alcançar objetivos de melhoria, tanto nos produtos quanto nos serviços prestados pelas referidas empresas, acarretando um melhoramento contínuo dos processos de produção.

Apesar dos recursos essenciais aqui serem principalmente humanos, Bauman (2001) expõe que enquanto na modernidade sólida o trabalho era a base do futuro, na modernidade líquida não há garantias nem seguranças, o que faz com que os profissionais do agora estejam em constante e dinâmica atividade intelectual, de melhoramento profissional e desenvolvimento do seu desempenho criativo e produtivo, já que o mercado de trabalho é cada vez mais efêmero. Sendo assim, os recursos humanos são transitórios.

A presente versão "liquefeita", "fluida", dispersa, espalhada e desregulada da modernidade pode não implicar o divórcio e ruptura final da comunicação, mas anuncia o advento do capitalismo leve e flutuante, marcado pelo desengajamento e enfraquecimento dos laços que prendem o capital ao trabalho. (BAUMAN, 2001, p. 171)

O aperfeiçoamento não é mais uma questão coletiva, não é mais pensado como parte de um projeto que visa aumentar os níveis de qualidade de vida, o aperfeiçoamento é agora parte das escolhas individuais, e precisa ser constante. 
Assim como o mercado não valoriza o indivíduo como ser humano único, os profissionais também se tornaram nômades, mudando constantemente para a empresa que mais lhe agradar.

Essa situação, de acordo com Bauman (2001), além de tornar os indivíduos inseguros, de fato os enfraquece, pois sem ações coletivas que poderiam fomentar alguma mudança, a abolição de diversos postos de trabalho é constante, e os prejudicados são os indivíduos, não as empresas.

Por todos esses fatores, a Formação Superior precisa ser sólida, ampla e global, onde o aluno se diplome apto a angariar sua vaga no mercado de trabalho, ou quantas vagas forem necessárias para seu subsídio financeiro ao longo da vida.

\section{Considerações finais}

Esse estudo se propôs a pensar a Gestão do Conhecimento e a inovação, pensando a aquisição dos conhecimentos necessários para a inserção no mercado de trabalho adquiridos no Ensino Superior.

A gestão do conhecimento foi entendida como processo de criação, disseminação e incorporação do mesmo, e vista como necessária no momento atual, diretamente relacionada às questões humanas contemporâneas.

A gestão do conhecimento é ampla e se inclui nos conteúdos necessários dos já tão repletos conhecimentos profissionais atuais, já que o homem de hoje precisa ter domínio amplo em todas as áreas de sua profissão: não só visão, mas também profundidade e aptidão global.

O texto descreve que quando o indivíduo atua em área que não lhe interessa, bem como assume função sem preparo, substituindo alguém já qualificado para a função, ocorre desperdício de talento, potencialidades, tempo e recurso financeiro.

Em contrapartida, para o melhor aproveitamento de todos esses recursos é necessário que o profissional tenha atitude, suporte, conhecimento, habilidade, experiência, metodologia, contexto adequado e competência no uso eficaz das tecnologias disponíveis.

Para a aquisição do conhecimento, a tecnologia é hoje uma ferramenta essencial, assim como o meio acadêmico, que forma a base do Ensino Superior do profissional, onde para refletir e executar existe a necessidade de gerir; quem organiza o preparo e o 
saber e ensina é o professor, por isso seu papel também é essencial na formação profissional.

A contemporaneidade demanda dos docentes novas práticas para preparar os alunos para o pensamento crítico e reflexivo, além do bom uso das tecnologias, com vistas para o futuro, já que hoje a riqueza vem do conhecimento; por sua vez, essa economia baseada no saber é uma tendência que tem recebido muito investimento através das pesquisas.

Outro aspecto que o estudo aborda é a extensão universitária, que aproxima o aluno da prática e estimula o contato com a comunidade através de trabalho social na sua área de estudo, sendo mais um caminho rumo a processos inovadores.

A inovação é um aspecto valorizado pelo mercado de trabalho, além do pensamento reflexivo, conhecimento específico e integração desse conhecimento, assim como os fundamentos ensinados no Ensino Superior; por tudo isso essa formação é fundamental: é essencial que o aluno conclua os estudos, e o estímulo para tanto também deve partir do professor.

No mundo atual, a formação é individual, é escolha particular, de acordo com desejos e aptidões, não é mais coletiva e social; nessas circunstâncias, tanto o mercado troca de profissional constantemente, quanto os profissionais mais qualificados e adaptáveis trocam de emprego regularmente.

A conclusão a que se chega é a necessidade da educação continuada, já que com tantas mudanças sociais, culturais, temporais e tecnológicas, a formação superior não basta para o profissional atual, que obrigatoriamente deve ser atualizado de forma constante, através de projetos e multitarefas, com a finalidade de possuir condições de executar quaisquer funções que lhes forem solicitadas.

AGRADECIMENTOS: À CAPES - Coordenação de Aperfeiçoamento Pessoal de Nível Superior

\section{REFERÊNCIAS}

ARAUJO, O. H. A.; RIBEIRO, L. T.; PINHEIRO, M. N. S. Tecnologias móveis nos processos de ensino e de aprendizagem. Revista Ibero-Americana de Estudos em Educação, Araraquara, v. 11, n. 1, 95-110, jan./mar. 2016. 
BACZINSKI, A. V. M.; COMAR, S. R. Gestão escolar democrática e a pedagogia histórico critica. Revista on line de Política e Gestão Educacional, Araraquara, v.20, n.2, p. 145-165, maio/ago. 2016.

BAUMAN, Z. A modernidade líquida. Rio de Janeiro: Zahar Ed., 2001.

BIZELLI, J. L. Inovação: limites e possibilidades para aprender na era do conhecimento. 1. ed. São Paulo: Editora Unesp/Cultura Acadêmica, 2013.

BRASIL. Constituição da República Federativa do Brasil. Artigo 207, 1988.

BRASIL. Lei de Diretrizes e Bases da Educação, 9.394/96, de 20 de dezembro de 1996.

DRUCKER, P. Administração de organizações sem fins lucrativos - princípios e práticas. Editora Pioneira, São Paulo, 1990.

ELIAS, A. A. Organizações inteligentes. Disponível em:

<http://www.rh.com.br/portal/mudanca/artigo/4758/organizacoes-inteligentes.html>. Acesso em: 15 out. 2016.

FIGUEIREDO, S. Gestão do conhecimento. São Paulo: QualityMark, 2005.

HILLESHEIM, B. Políticas públicas e educação. Revista Ibero-Americana de Estudos em Educação, Araraquara, v. 10, n. 3, p. 788-796, 2015.

KUHN, T. S. A estrutura das revoluções científicas. 5 ed. São Paulo: Ed. Perspectiva, 1998.

LEVY, P. Cibercultura. São Paulo: Ed. 34, 1999.

LIBÂNEO, José Carlos. Educação escolar, políticas, estruturas e organização. 2 ed. SP: Cortez, 2005.

OCDE - Organização para a cooperação econômica e desenvolvimento. Manual de Oslo. $2^{a}$ ed., 1997.

NONAKA, I.; TAKEUCHI, H. Criação do Conhecimento na empresa: como as empresas geram a dinâmica da inovação. Rio de Janeiro: Campus, 1997.

PASQUALINI, F. R.; MARTINS, R. C.; MIGUEL, J. C. O compromisso do profissional em formação com a sociedade. Revista Ibero-Americana de Estudos em Educação, Araraquara, v. 11, n. 2, p. 644-666, abr./jun. 2016.

PEGORINI, M. L.; GURGEL, D. As políticas de acesso e permanência na Educação Superior. Revista on line de Política e Gestão Educacional, Araraquara, v.20, n.1, p. 21-37, jan-abr/2016.

SENGE, P. M. A quinta disciplina: arte e prática da organização que aprende. São Paulo: Editora Best Seller, 2002. 
TSALLIS, Constantino. Por que pesquisa na Universidade? Ciência e Cultura, v. 37, n. 4, p.570-572, abr. 1985.

VIDAL, K. D. B.; NETO, I. R. Políticas educacionais orientadas à inovação. Revista on line de Política e Gestão Educacional, Araraquara, v.20, n.2, p. 257-270, maio/ago. 2016.

\section{Como citar este artigo:}

CUNHA, Arielly Kizzy; SANTOS CRUZ, José Anderson; BIZELLI, José Luís. A gestão do conhecimento e as expertizes desenvolvidas no ensino superior. Revista on line de Política e Gestão Educacional, Araraquara, v.21, n. esp. 1, p. 677-690, out $/ 2017$. Disponível em: <http://dx.doi.org/10.22633/rpge.v21.n.esp1.out.2017.10442>. ISSN: 1519-9029.

Submetido em: 10/04/2017

Aprovado em: 18/09/2017 